\title{
Living with Corruption in Central and Eastern Europe: Social Identity and the Role of Moral Disengagement
}

\author{
Katalin Takacs Haynes ${ }^{1} \mathbb{D} \cdot$ Matevž (Matt) Rašković ${ }^{2}$
}

Received: 1 November 2019 / Accepted: 20 August 2021 / Published online: 4 September 2021

(c) The Author(s), under exclusive licence to Springer Nature B.V. 2021

\begin{abstract}
We examine corruption across three Central and Eastern Europe (CEE) countries (Hungary, North Macedonia and Slovenia) through a social psychology framework which integrates social identity theory, social cognitive theory and moral disengagement mechanisms. We illustrate how various social identities influence individual and collective action in terms of ethical behavior and corruption, thereby creating, maintaining and perpetuating petty, grand and systemic public/private corruption through triadic co-determination via cognition, behavior and the environment. Despite growing research on corruption normalization, less is known about the cognitive and behavioral mechanisms in ethical decision making, the cognitive workings of how individuals reconcile unethical behavior and the social psychological processes behind corruption in society and organizations. Expert interviews reveal internally conflicted multi-layered social identities perpetuating corruption, some embedded in nationalistic history and others tied to the European Union, which supports the divergent paths of CEE countries since the fall of communism. Some moral disengagement mechanisms are common across all three countries, while others are linked to specific circumstances. Social identity mechanisms feed into moral disengagement, which individuals draw upon to reconcile the conflict between unethical behavior and moral codes. Patterns of moral disengagement aggregate to the country level and explain normalization of corruption in CEE society and organizations.
\end{abstract}

Keywords Corruption $\cdot$ Central and Eastern Europe $\cdot$ Social psychology framework $\cdot$ Social identity theory $\cdot$ Moral disengagement $\cdot$ Expert interviews

\section{Introduction}

Central and Eastern Europe (CEE) has offered fertile ground to explore institutional idiosyncrasies of post-transition markets via research at the nexus of sociology and international business (Rašković et al., 2020) which includes ethics and corruption (Steger et al., 2017). Contrary to research on

Katalin Takacs Haynes and Matevž (Matt) Rašković contributed equally to the manuscript.

Katalin Takacs Haynes

ktakacsh@udel.edu

Matevž (Matt) Rašković

matevz.raskovic@vuw.ac.nz

1 Department of Business Administration, Lerner College of Business and Economics, University of Delaware, 210 Lerner Hall, Newark, DE 19716, USA

2 School of Marketing and International Business, Victoria University of Wellington, 23 Lambton Quay, Rutherford House, Level 11, 1115, 6011 Wellington, New Zealand cultural, institutional and other macro-environment antecedents/determinants of ethical behavior, the "research on the individual-level factors that predict individuals' propensity to morally disengage" to justify or reconcile unethical behavior (Bandura, 1999) is still new, particularly regarding organizational and economic contexts (Newman et al., 2019, p. 21). In terms of normalized corruption, we also know less about "the purposive action of individuals and organizations aimed at creating, maintaining and disrupting institutions" (Lawrence \& Suddaby, 2006, p. 215), which is part of the institutional work strand, than we do about the constraining/enabling "game rules" nature of institutions within old institutionalism or institutional economics (Aguilera \& Grøgaard, 2019).

Despite the appeal of social cognitive theory (Bandura, 1986), which explores the interplay between people, social groups and behavioral influences (Newman et al., 2019), limited research takes a qualitative approach to unethical behavior (Castro et al., 2020). The same holds for exploring macro-environmental determinants of moral disengagement 
(Newman et al., 2019), including "sanctioned collective action" and officially condoned corporate corruption (Brief et al., 2001, p. 472). For example, peer influence explains $35 \%$ of the variance in ethical decisions, while culture explains only $1.3 \%$ (Westerman et al., 2007). Thus, exploring corruption via social groups is crucial. The lack of "contextualized theoretical analysis" (Vergara, 2019, p. 3) helps explain why over half of the examined countries in Transparency International's corruption rankings would receive failing school grades (Vergara, 2019).

Increasingly, convergent and divergent regional processes have reduced CEE's relevancy as a geographic entity with a shared identity (Rašković et al., 2020). The dominant theoretical lens to study CEE markets, corruption and ethical behavior has been old institutionalist theory or institutionalist economics (Rašković et al., 2020) and culture value theory (Westerman et al., 2007). These theoretical perspectives provide valuable insights into emerging markets (Rašković et al., 2020), changes in value-based business practices (Padelford \& White, 2010) and the evolution of ethics against the backdrop of transition (Bohatá, 1997; Filatotchev et al., 1994). However, less is known about cognitive and behavioral mechanisms for successfully navigating the reality-idealism dichotomy within ethical decision making (Padelford \& White, 2010), about the cognitive workings of how individuals reconcile unethical behavior (Newman et al., 2019) or about the social psychological processes behind corruption (Zyglidopoulos \& Flemming, 2008).

Motivated by the dichotomy of CEE's ethics in the face of socioeconomic and political transition (Fülöp et al., 2000), we build on social identity and social cognition theories to explore the following research question: How do sociocognitive processes related to moral disengagement and social identity-based behaviors help explain corruption in CEE? Drawing on social identity theory (SIT) (Tajfel \& Turner, 1979) and social cognitive theory (SCT) (Bandura, 1986), we explore moral disengagement, which is a set of mechanisms individuals use to engage in cognitive reframing to simultaneously hold high moral standards while acting unethically/being exposed to moral violations (Newman et al., 2019). We explore how moral disengagement is shaped by various types of social identity in an environment of normalized organizational and societal corruption (Brief et al., 2001). We aim to clarify the largely unexplored interplay between social (group) identification, individual cognition and behavior in CEE (Newman et al., 2019). Our approach is supported by nine in-depth, semi-structured systemizing interviews with corruption experts from Hungary, North Macedonia and Slovenia. We adopted the systematizing expert interview approach from the expert interview method family (Bogner \& Menz, 2009; Bogner et al., 2018) to obtain "systematic and complete information" from experts with exclusive and reflexive knowledge (Bogner \& Menz, 2009, p. 47). Such qualitative research can substantially advance corruption research (Castro et al., 2020).

We make three contributions to the business ethics and corruption literature. One, we explore specific moral disengagement mechanisms at the macro-environment level to understand corruption nuances in CEE countries. A review and research agenda outlined by Newman et al. (2019) reveals this remains uncharted territory. Two, linking moral disengagement with SIT can help explore the specific mechanisms associated within the so-called "social psychology of evil" (Zyglidopoulos \& Flemming, 2008, p. 267) which has been so far applied to CEE corruption research in limited capacity. The social psychology of evil unpacks institutional and socialization processes like indoctrination and rationalization to explore the nature of societal actors who actively engage, enable, or allow as inactive bystanders persistent, extreme and destructive human behavior (Staub, 1999). We also extend Westerman et al.'s (2007) seminal work on cultural and peer influences behind corruption. Three, we provide an identity-based understanding of (un)ethical behavior in CEE through a non-positivist sociocognitive corruption lens (Vergara, 2019). We draw on the institutional work strand of institutional theory (e.g., Lawrence \& Suddaby, 2006) which adopts a less structuralist view and "focuses explicitly on the role of individuals as agents" (Aguilera \& Grøgaard, 2019, p. 27).

Next, we first briefly introduce the three CEE countries. We review SIT, SCT (moral disengagement) and corruption literatures (including the one that focuses on CEE) as part of our theoretical framework. We describe our methodology, data and findings from nine systemizing expert interviews. We then present an integrated social psychology framework ${ }^{1}$ which illustrates different moral disengagement mechanisms, various types of social embeddedness, and social identity-based behavior related to corruption, as well as how self-enhancement, optimal distinctiveness and reduced uncertainty motivate them. Finally, we discuss the implications and limitations of our study and provide guidance for future research.

\section{Country Settings}

Hungary, North Macedonia and Slovenia were selected for their historical, cultural, political and cognitive types of embeddedness pertinent across CEE (Rašković et al.,

\footnotetext{
1 We have developed a non-positivist framework to inform/guide thinking about the sociocognitive aspects of people and organizations living with normalized corruption. It also builds on the logic of the institutional work strand of institutional theory, which adopts a less structuralist view of institutions and focuses more on individual actor agency.
} 
2020). They are small CEE countries with parts of common history (i.e., Austro-Hungarian empire, Ottoman occupation). They represent different transition archetypes (i.e., Hungary as Europe's enfante terrible, Slovenia as a victim of early transition success, and North Macedonia as an EU-candidate country overtaken by organized crime and haunted by its ancient glory). In terms of corruption performance, they occupy different positions on the corruption spectrum. According to Transparency International (2019), North Macedonia's CPI score of 35/100 is the same as the average score for the East European and Central Asia group of countries. Hungary's CPI score of 44 is comparable to the average CPI score of all 180 countries, while Slovenia's CPI score of 60 is more consistent with the average CPI score for Western Europe. Unlike Visegrad countries, which Hungary is part of, North Macedonia and Slovenia have received much less corruption research attention.

Based on our framework, we propose that various embeddedness types in our three CEE countries have uniquely shaped individuals' sense of self, social identities and moral standards, thus perpetuating conflict between the environment, individual behaviors and cognitions. Individuals routinely rely on moral disengagement mechanisms to navigate this "triangle." Through this process, they create, sustain and sometimes challenge normalized corruption (Ashforth $\&$ Anand, 2003; Brief et al., 2001).

Hungary is a member of the Visegrad group, has a population of almost 10 million and has been the beneficiary of large-scale EU foreign direct investments (FDIs). In a 2017 Eurobarometer corruption report, Hungary ranked first by percentage of the population (59\%) believing that favors for a public official in exchange for services were acceptable (22\% EU average). Hungary increasingly defies EU values and ignores warnings regarding its political and institutional landscape (Lendvai, 2019). In 2018, this resulted in the first formal EU sanctions invoking the infamous Article \#7 of the EU Treaty.

North Macedonia is a small EU-candidate country of 2 million in the Western Balkans. Unlike Hungary and Slovenia, which are EU member states, North Macedonia is part of the so-called East European and Central Asia group within Transparency International's Corruption Ranking (2019). This group of countries has the second-worst average CPI score of 35 (following Sub-Saharan Africa). Positioned at the historical and cultural cross-roads of Southeast Europe and the "Orient", it is riddled with paradoxes. Consistently ranked among the 10 best countries for ease of business, it has a turbulent political landscape, ethnic tensions with its Albanian minority, a turbulent accession to the EU (i.e., name change issues), the most significant population brain drain in Europe and a surreal transformation of its capital into a grandiose ethnocratic theme park (Vangelov, 2019).
Slovenia is a small EU member country with a population of 2 million, long lauded for its successful CEE transition and accession to the EU, NATO and the Eurozone (Bugaric \& Kuhelj, 2015). Its reservedness towards FDI combined with its lack of systematic structural reforms and its "neocorporativist" institutional system made it fall victim to unsuccessful managerial buyouts and institutional gridlock, causing a painful fall from its CEE "wonderchild" throne (Rašković et al., 2020).

Despite their cultural, institutional and economic differences, the three countries share a common regional history going back to the arrival of Christianity in the tenth century. Later, each was influenced to varying degrees by power struggles within and between the Austro-Habsburg and Ottoman empires. After WWII, under a socialist ideology, the three countries were turned into unique CEE socioeconomic experiments (Rašković et al., 2020). Diverging post-communist paths followed. Their shared and unique histories yielded complex and layered identities, qualifying them for management scholarship's "interesting and important" designation (Tihanyi, 2020).

\section{Corruption in Central and Eastern Europe: Phenomena and Literature Review}

We first classify various forms of corruption and summarize the current literature on corruption, with particular attention toward transition contexts and corruption in CEE.

\section{On Corruption: Classification and Current State of the Literature}

Defined as a misuse of authority for personal or organizational gain (Ashforth \& Anand, 2003), corruption is a "multidisciplinary subject" represented by "a substantial but scattered body of literature" (Bahoo et al., 2020, p. 1). A fundamental distinction conceptually exists between public corruption (involving government officials and politicians) and private corruption (involving managers, employees or firms) (Bahoo et al., 2020). Such distinctions may be clear in developed markets, but public and private spheres of influence are often blurred within CEE markets due to the markets' socialist history and socioinstitutional transformation, like privatizing socialist ownership (Filatotchev et al., 1994). The opportunistic and extractive behavior as a form of economic ethos (Padelford \& White, 2010) has also appeared amongst a context of various social identity issues and politics of identity (Rašković et al., 2020).

Public and private corruption can be further classified as grand or petty (depending on the scale) and as organized or unorganized (depending on the level of planning) (Bahoo et al., 2020). Particularly relevant to managerial 
decision-making is the distinction between pervasive (certain, known) and arbitrary (uncertain, changing/unknown) corruption (Rodriguez et al., 2005). Cuervo-Cazzura (2008) shows that firms investing in transition markets prefer arbitrary corruption over pervasive corruption to avoid known additional costs (pervasive) in favor of additional uncertainty (arbitrary corruption).

Contextualizing corruption helps challenge mainstream management theories (Bahoo et al., 2020). Institutional theory is particularly relevant, and research on corruption in transition economies has relied heavily on it (Jiménez et al., 2017) to help understand the role of institutions in emerging markets (Rašković et al., 2020). More recently, the use of institutional theory interested in individual-level agency and social group processes (as opposed to structures and outcomes) has motivated a shift from "thin" to more "deeper" application of institutional theory (Aguilera \& Grøgaard, 2019). Our work further explores corruption's normalization (Ashforth \& Anand, 2003; Brief et al., 2001; Castro et al., 2020; Spicer, 2009). As Ashforth and Anand (2003) note, corruption involves misuse that occurs in a social setting and involves collective actions (Brief et al., 2001) that create, reinforce and sometimes challenge social structures (Spicer, 2009).

\section{Literature on Corruption in Central and Eastern Europe}

Research focused on CEE has advanced institutional theory and laid the theoretical groundwork for research on emerging markets (Rašković et al., 2020). Topics include the specifics of CEE management (Steger et al., 2017) and the organizational capabilities of CEE firms (Dixon et al., 2010), including work, organizational change (Soulsby \& Clarke, 2007), knowledge management (Uhlenbruck et al., 2003) and corruption (Brown et al., 2003; Cuervo-Cazzura, 2008; Jiménez et al., 2017; Padelford \& White, 2010).

Filatotchev et al. (1994) challenged the black and white ethics of management buyouts and social justice in emerging markets, highlighting the distribution of benefits and the potential risks of unethical behavior from institutionalized and normalized corruption. The authors established managers as "agents of social and economic reform" (Filatotchev et al., 1994, p. 531), linking corruption to social identity theory and social agency. This perspective was displaced by a narrative of corruption as a policy issue, emphasizing negative economic consequences (Vergara, 2019) amongst an emerging socioeconomic ethos of transition (Padelford \& White, 2010). In the late 1990s, Bohatá (1997) adopted a phenomenon-based approach, teasing out "major problems and challenges brought about by the profound reforms to these societies and economies" (p. 1571) and underscoring institutional voids. Enderle (1997) observed that business ethics are a critical "social institution" which includes "a concentration of social forces [...] in support of the moral quality of decision processes" (p. 1482). In the context of CEE, this requires sensitivity to historical legacies, an understanding of sociocognitive differences across societies and an appreciation of semantics.

Both SIT and moral disengagement are highly relevant in this regard for understanding social agency and underlying cognitive processes related to corruption. "( $\mathrm{T})$ he lack of sophistication with which the politicians, government officials, generals, and other Third World influentials practice their craft" (Khera, 2001, p. 33) perpetuated a narrative of "otherness", where culture, religion and philosophy were explored via the (ir)rationality of managerial ethics (Brouthers et al., 2008). Studies of normalized corruption in CEE (Spicer, 2009) were expanded to include the literature exploring the "social psychology of evil" with its focus on institutional and socialization processes, in which corruption in CEE can be explored along a "continuum of destructiveness" with specific social and cognitive mechanisms (Zyglidopoulos \& Fleming, 2008, p. 267). Zyglidopoulos and Fleming focused on ethical distance and acknowledged the importance of social psychology processes, particularly "broader contextual mechanisms, like socialization" (2008, p. 269). Bandura's (1986) triadic co-determination and SIT's meta-theoretical toolkit combined with a non-positivist qualitative approach can help unpack such contextual features and explore their sociocognitive mechanisms.

\section{Social Identity Theory}

SIT is a social psychology meta-theory (Abrams \& Hogg, 2004) for exploring various phenomena related to "intergroup relations, group processes, and the social self" (Hogg et al., 1995, p. 259). For Tajfel and Turner (1979), social identity captured the emotional and cognitive value of knowing that one belongs to a social group. SIT is shaped by social interactionism and draws on two crucial sociocognitive processes (Hogg et al., 1995): social categorization (via extenuating intergroup boundaries) and self-enhancement (self-evaluation via positive in-group stereotyping and norms relative to the out-group). Three key motivational mechanisms underpin SIT (Hogg, 2006): self-enhancement, optimal distinctiveness and uncertainty reduction. These form the core of our triadic co-determination framework in Fig. 1.

\section{Self-enhancement and Self-esteem}

Self-enhancement is an attempt to increase a positive selfconcept and to mitigate its erosion. Self-enhancement draws on categorization theory and self-categorization, which 
Fig. 1 Triadic co-determination framework of corruption
THE ENVIRONMENT

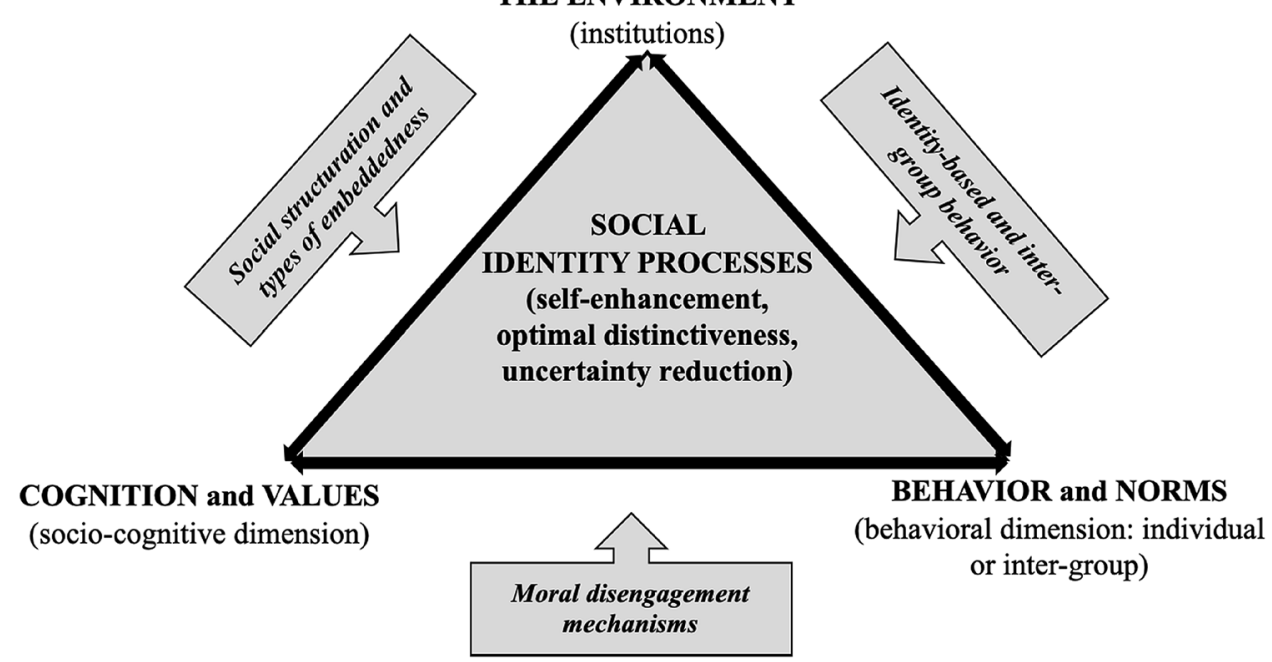

Abrams and Hogg (1990) formalized in the self-esteem hypothesis. Self-esteem can come from enhanced social identity based on positive distinctiveness and intergroup discrimination, making it a dependent construct. Eroding self-esteem and threatening social identity, however, can motivate intergroup discrimination (Abrams \& Hogg, 1990), making it an independent construct. This two-way process depends on several other factors, such as identification with the in-group, the salience of employed social categories, the relevance to group identity of the comparative dimension, the degree of comparability between groups and the status differential between the in-group and out-groups (Hogg et al., 1995).

Many contingent factors interact with the specific type of invoked self-esteem (i.e., personal/social, trait/state, global/ specific self-esteem), like perceived threat level, self-esteem extremity or the strength of group identification (Hogg, 2006). Populist politicians, especially in CEE, often misuse social identification to prey on the lower socioeconomic strata of a population to support contradictory policies in their interest. They often erode competitiveness and welfare and institutionalize neo-corporativism and state capture based on a false promise of rejuvenated national identity and higher self-esteem due to discrimination against the "others" (Rašković \& Takacs Haynes, 2020).

\section{Optimal Distinctiveness}

Optimal distinctiveness concerns a balance between the need to be "part of something" (via group membership, linked to social self-esteem) and to be unique/have autonomy (achieved through individuality, linked to personal self-esteem) (Hogg et al., 1995). The concept of optimal distinctiveness evolved from positive distinctiveness, which concerned out-group degradation. Optimal distinctiveness, however, focuses more on in-group distinction (Choi \& Hogg, 2020). Group distinctiveness can be threatened by strong competition and high-status out-groups (Abrams \& Hogg, 1990). It can also be weakened by a stronger personal self-identity (Hogg et al., 1995).

\section{Uncertainty Reduction}

Uncertainty reduction's role within SIT draws on heuristics and on general motivation via uncertainty reduction in human behavior (Hogg, 2006). According to uncertainty-identity theory (see Choi \& Hogg, 2020), self-uncertainty, relational uncertainty and collective uncertainty facilitate social categorization through metacontrasting and prototyping. Reducing uncertainty via promotive and pre-emptive identification with entitative groups and prototypical leaders (offering predictability through prescribed behavior) is another touchpoint between SIT and moral disengagement (Hogg \& Terry, 2000). This directly affects corruption research because peer influence is a much stronger antecedent of ethical decision-making than culture (Westerman et al., 2007).

Recently, uncertainty-identity theory has been applied "to explain radicalization, populism, social disintegration, and extremist group behavior", as well as social agency and change (Choi \& Hogg, 2020, p. 483). These processes are highly relevant for CEE countries. Rapidly changing social contexts (e.g., growing inequality), technological and social changes and economic and political crises further exacerbate one's sense of uncertainty (Choi \& Hogg, 2020), leading to a vicious circle. 


\section{Social Cognitive Theory and Moral Disengagement}

According to Bandura (2016), "the nature and function of morality is embedded in a broader social cognitive theory of human agency" (p. 4). In sociocognitive theory, also known as the social cognitive theory of moral agency (Newman et al., 2019), human agency is observed through three mechanisms: (1) forethought, or planning and self-guidance towards a planned future, combined with self-sanctioning of transgressive behavior; (2) selfreactiveness, or the evaluative process that follows constructing and conducting action against previously adopted and internalized codes of conduct; and (3) self-reflection, a meta-cognitive process during which individuals evaluate their own thoughts and actions and the values on which they are based (Bandura, 2016).

SCT examines individuals' cognition and associated behaviors, and the social and physical environment in which both manifest via a three-way interactive causation, called triadic co-determination (Bandura, 1986, 2016). According to Bandura, personal influences (e.g., identity, values, cognitions, emotions and attitudes) affect how a person behaves and the person's (social) environment. A person's behavior can be physical, emotional or social, and it may alter, create or maintain the environment in which it is performed. Finally, the environment can be imposed, selected or created and might refer to social and physical contexts, such as organizations (Bandura, 2016). The environment can influence the personal and behavioral aspects of human functioning. The triadic interplay between personal, behavioral and environmental determinants provides the context for moral agency and moral disengagement. Moral disengagement (Bandura, 1986, 1999) describes the mechanisms by which individuals engage in cognitive reframing, allowing them to simultaneously hold high moral standards while acting unethically (Newman et al., 2019) (see Fig. 1).

According to Bandura $(1999,2016)$, the moral self and self-regulatory functions are part of the sociocognitive self. Individuals adopt standards of right/wrong and behave in accordance with those internalized standards. Behavior that aligns with the notion of "right" increases individual self-worth (Bandura, 2016). In contrast, individuals refrain from acts violating their standards to avoid moral condemnation. Moral agency, the self-sanctioning of good and bad behavior, is both inhibitive and proactive (Bandura, 2016): it prevents individuals from committing immoral acts and promotes humanitarian acts. Yet, individual moral agency also allows people to maintain their moral standards and self-respect while committing immoral or unethical acts that would normally violate their values-based morals. Individuals decouple, or disengage, from their morality in various contexts after committing large-scale inhumane acts and small everyday acts against their moral codes.

Moral disengagement has been studied at the individual, team and organizational levels across different research contexts (Bandura, 2016; Moore, 2008; Newman et al., 2019). The mechanisms of moral disengagement operate at four distinct loci: behavioral, agentic, outcome and victim (Bandura, 1986, 2016). Appendix 1 lists moral disengagement mechanisms and their definitions for reference.

\section{Social Identity Theory, Social Cognitive Theory and Corruption}

SIT expanded its focus from social motivations and intergroup relations to study intergroup emotions (investing in one's social identities), social harmony, social development, collective behavior and social change (Choi \& Hogg, 2020). It is increasingly being applied to study organizational phenomena (Rašković \& Takacs Haynes, 2020). In this study, we examine corruption and dirty practices in three CEE countries via SIT and SCT, combining social and moral agency.

The framework in Fig. 1 follows a non-positivist logic. It aims to systematize the general logic of Bandura's (1986) triadic co-determination, which we apply to corruption. Based on the cognition-behavior-environment logic, the framework integrates (1) the role of individual cognition and values with respect to corruption, (2) the importance of the (social) environment in which corruption occurs/comes from, and (3) the manifested unethical behavior shaped by individual and group norms. In this triangle, moral disengagement mechanisms are employed as a set of rationalizing mechanisms linking the sociocognitive and behavioral aspects of corruption, while types of embeddedness and the underlying social structuration processes link the sociocognitive dimension of corruption and the (social) environment through the constraining, enabling, or challenged role of co-created institutions by purposeful actors in a process of social structuration (Aguilera \& Grøgaard, 2019). Lastly, corruption's environment and behavioral aspects are linked via identity-based and intergroup processes. At the center of the triangle are the motivational mechanisms associated with SIT driving social agency and connecting to moral agency through moral disengagement via the concept of self-worth. The framework illustrates that, as an interactionist metatheory, SIT is useful for studying corruption and unethical behavior in societies undergoing socioeconomic and political change, particularly because of its unexplored link to moral disengagement. This link occurs through the common 
social cognitive theory background of morality and ethics (Hogg \& Terry, 2000).

\section{Methodology and Data}

\section{Methodology}

Trying to understand the sociocognitive nature of corruption associated with moral disengagement mechanisms in CEE, we employ a qualitative research approach from social psychology that allows us to approach phenomena holistically (Power et al., 2018). Expert interviews are appropriate for exploring social identity issues and follow the nonpositivist research traditions of constructivism (e.g., social identity construal, activation of cognitive schemas etc.) and of interpretivism (e.g., a focus on justification and meaning) (Brand, 2009). Such a qualitative approach resolves the tension between qualitative research's ability to develop a nuanced perspective of corruption and the social undesirability inherent in corruption research that renders more traditional research methods "difficult, dangerous or unethical" (Castro et al., 2020, p. 959).

Expert interviews have a tradition in political and social science research since the 1990s, particularly in Europe (Bogner et al., 2018). However, they are more a family of qualitative research methods than a single interview method (Bogner et al., 2018). Experts are selected "by virtue of their specific knowledge, their community position, or their status" (Döringer, 2020, p. 1). Experts can also be selected for their technical, procedural or contextual knowledge (Bogner et al., 2018). A few experts can yield adequate results, as confirmed by research on global reputation, for example (Highhouse et al., 2009).

In social science research, experts can bridge analysis, evidence and practice, particularly when discussing taboos or sensitive issues (Bogner et al., 2018). This is why international non-governmental organizations, such as Transparency International and the OECD, often rely on experts to assess corruption (Huberts, 1998).

Bogner et al. (2018) and Bogner and Menz (2009) distinguish between three types of expert interviews with different epistemology. Exploratory expert interviews offer knowledge and orientation in unfamiliar fields for generating first hypotheses/research questions. Theory-generating expert interviews generate theory based on the "subjective action orientations and implicit decision-making maxims of experts" (Bogner \& Menz, 2009, p. 48). Our approach falls into the most widely used third category, namely, systematizing expert interviews which offer exclusive, systematic and holistic reflexive knowledge. Systematizing expert interviews are "oriented towards gaining access to exclusive knowledge possessed by the expert" and related "knowledge of action and experience, which has been derived from practice [as a recognized expert]" (Bogner \& Menz, 2009, pp. 46-47). It is important to stress that experts are not themselves investigated subjects but act as guides providing specialized knowledge "about the real subjects being investigated" (Bogner \& Menz, 2009, p. 47). This holds important implications for how information is analyzed. Systematizing expert interviews can be much more structured than, for example, exploratory expert interviews, which is also why they seldomly involve traditional coding procedures.

Our constructionist approach links knowledge of reality to communication, and the "general understanding of social reality as a social construct" (Froschauer \& Lueger, 2009, p. 217). Froschauer and Lueger (2009) reference Weick's (2003) notion of enactment to describe the process by which an actor not only changes, or develops as a result of its environment, but also is a purposeful participant in creating and shaping the environment.

\section{Data Sources}

Our study comprises nine expert interviews. Following Human Ethics approval by the Institutional Review Board at the project's coordinating university, three experts were selected from each country for their technical and contextual knowledge, as well as their community position and recognized expertise (Bogner et al., 2018). For each country, one expert was the local head of a global anti-corruption non-governmental organization. The second expert was an expatriate professor with a social science $\mathrm{PhD}$ from the target country who could provide an insider/outside perspective on corruption. The third expert from each country was an investigative journalist or analyst reporting on corruption and fraud. As Castro et al., (2020, p. 960) note, "investigative journalists and the corruption they expose can be another valuable source of data." We matched the experts' backgrounds to collect similar data from each country.

We maintained a gender balance of at least one female and one male respondent for each country. Ultimately, we had five female and four male respondents. The experts were guaranteed anonymity. Creating a balanced and matched set of experts from three CEE countries involved extensive systematic background checks, research and professional networking. Creating a matched set of experts was a significant challenge, because it required simultaneous positive responses from three individuals with similar backgrounds. The countries' small sizes provided limited pools of potential experts on corruption.

The experts were asked to participate in a structured interview protocol specific to the systematizing type of the expert interview (Bogner \& Menz, 2009). Interviews followed a dialogic-discursive structure, drawing upon a structured interview guide with specific follow-up questions. The 
precise interview protocol has been made available as a supplementary online file to this publication for those interested in gaining a more detailed understanding of the types of questions employed.

Interviews were conducted between October 2019 and July 2020 with follow ups in early 2021. Interviews lasted 1.5-2 $\mathrm{h}$ and were conducted online in English due to geographic distance and COVID-19. All interviews were cloud recorded and transcribed. Transcription accuracy was verified before text analysis. Respondents were fluent in English and had several years of experience with corruption in CEE. In-country and expatriate corruption experts helped identify themes of moral disengagement, social identity, and behaviors linked to corruption. Comparable qualitative field research from the health sector shows that six to ten semi-structured interviews can produce thematic saturation (O'Reilly \& Parker, 2013). In the tradition of the systematizing expert interview method, the co-authors followed a twostep general thematic analysis and interpretivist approach. First, each researcher independently identified themes and categories in the transcripts, which was followed by systematic cross-verification between the researchers. The coauthors then interpreted the findings against the framework presented in Fig. 1.

\section{Analysis: Living with Corruption in Three CEE Countries}

Using quotes from nine expert interviews, we unpack corruption and unethical behavior in CEE. The expert interviews illustrate how our triadic co-determination framework applies to corruption as a social institution (Enderle, 1997) underpinned by complex social psychological mechanisms (Zyglidopoulos \& Flemming, 2008). We first present quotes describing the current environment, emphasizing the role of organizations and of the government. Next, we offer explanations of the historical, economic and social sources of social identity and of corresponding behaviors. Our country sections close with specific illustrations of moral disengagement mechanisms and show how individuals reconcile unethical behavior with normalized everyday corruption.

\section{Hungary}

"Ethics in the Hungarian economic life is a delusion rather than a reality." (Fülöp et al., 2000, p. 5)

Our interviews generally reveal that Hungarians' social identity is historically multi-layered and internally conflicting. Hungarian social identities rooted in various historical perspectives and socioeconomic backgrounds create intergroup fault lines between older and younger generations and between elites with connections and non-elites. Some social identities appear linked to periods or events in Hungary's 1000-year turbulent history. The most important such moment is the 1920 Trianon Treaty, a direct result of the Austro-Hungarian Empire's loss of WW1 (Lendvai, 2003). Referred to as "Trianon Trauma" by two experts, the treaty still mars the Hungarian psyche as a painful reminder of losing $71 \%$ of its territory and $64 \%$ of its population. Current prototypical populist politicians, like Viktor Orban, leverage the event to increase nationalist sentiment and gain legitimacy.

In the 1930s Hungary swung to the far right and became an ally of Nazi Germany. After WWII, Soviets ruled Hungary until 1989 (Lendvai, 2003). A rigorous privatization process after communism's fall was accompanied by an influx of FDI, perceived by many as a loss of economic sovereignty. Despite EU membership in 2004, Hungary's democratic institutions eroded after 2010, with populist nationalist politics rendering it the EU's enfant terrible.

Our experts agree with previous findings regarding corruption and dirty practices in Hungary. Ordinary Hungarians' everyday life involves an ever-changing system of corrupt and unethical practices with strong historical embeddedness (Enderle, 1997) and self-reinforcing destructiveness spirals (Zyglidopoulos \& Flemming, 2008). This interaction connects the highest levels of government and the lowest levels of private businesses. Paralleling Bandura's triadic co-determination logic, the illustrative quotes show how the general population's behavior and subsequent perpetuation of the system are motivated by deeply held understanding of corruption as a normalized social psychology of survival. The experts note that, from a self-efficacy perspective (Bandura, 1982), Hungarians do not think they can change the system and lack social agency. Individuals resolve unethical behaviors via multiple moral disengagement mechanisms related to the initiation, facilitation and reconciliation of corruption (Moore, 2008). Our expert interviews illustrate how all three SIT motivational mechanisms (i.e., selfesteem, positive distinctiveness and reduced uncertainty) feed strongly into Bandura's (2016) triadic co-determination logic, perhaps the most extensively among the three studied countries.

The environment, a cornerstone of our theoretical framework, is represented by institutions, organizations, companies, the government and the corrupt or dirty practices that occur therein. In Hungary, petty and grand corruption are rampant. Experts have described widespread practices typical of both corruption types, noting that the business sector actively participates by not providing invoices to the public while providing kickbacks to government. According to Expert \#1, the public's behavior reinforces norms and perpetuates corrupt practices in the business sector in the form of petty corruption, which 
is often related to invoicing and VAT (at 27\%) evasion. According to Expert \#1, grand corruption, which occurs at the intersection of government and business, is common: "(...)for example, the kickbacks and fraud in the public procurement and overpricing the public procurement procedures."

Grand corruption provides favorable access to the business sector. According to Expert \#2, "the most important problem is that (...) people who are close to the government can win in the tender or have access to these infrastructure investments." In exchange for kickbacks, "the government people (...) get back money from big investments, highways, or stadiums," even if just 1\% (Expert \#2). Our experts also pointed to the systemic problem of state capture, which is often closely related to FDIs (Fazekas \& Toth, 2016) and reinforces institutionalized corruption:

"(It) is what we call the state capture (...) when the system itself is rigged, so when the corrupt practices are not the dysfunction of the system, but the system is itself is rigged, really in favor of those who are in power, in favor of the, elite." (Expert \#1)

There has also been a notable shift from petty corruption based on Soviet influences to institutionalized grand corruption under Viktor Orban:

"So in the last 30 years, (...) corruption was always present, at a relatively high level in the Hungarian society and economy. (...) Until 2010 it was rather the petty corruption and kind of decentralized corruption (...) But this system rigging, it started in such an institutionalized way, in 2010. (...) the nature of corruption changed." (Expert \#1)

Embeddedness and social structuration are reflected in Hungarians' belief that anyone who is voted into office or otherwise gains power will undoubtedly become "corrupt sooner or later" (Expert \#1). However, "people, despite knowing that, they vote for the current government" (Expert \#2). Expert \#1 added, "that makes a legitimization to the ordinary people to be involved in corrupt practices." This setting provides the context for everyday Hungarians' social identities, cognitions and behaviors, illustrating low self-efficacy.

According to Experts \#1 and \#2, Hungarians identify strongly as European and want to shed the remnants of their relationship with Russia. Social identities rooted in Hungary's past and its current embeddedness in the EU illustrate optimal distinctiveness among members of the young generation, who identify as EU citizens and Hungarians. Conversely, the older generation feels a stronger affiliation with Hungary's nationalistic past, linked to Trianon: "Trianon was a catastrophe for Hungary, we lost more than two thirds of the territory. (...) We lost everything” (Expert \#2).
Expert \#1 made an additional point in terms of collective self-esteem (Abrams \& Hogg, 1990) regarding "self-victimization that derives from the Trianon trauma." Expert \#3 also mentioned the victim mentality as a defining trait alongside the self-enhancing trait of being smart and clever: "being clever and smart is one thing that you might need to game the system." This is a unique Hungarian trait connected to self-esteem and optimal distinctiveness. Hungarians have a conflicted relationship with the state indicative of how social identity (victimhood, cleverness) motivates moral disengagement (justification):

"Hungarians expect a lot from the state, much more than most of the Visegrad countries (...). So, people expect their wealth, not necessarily from themselves, but from the state. [But] (...) people like to cheat the state. (...) and it is considered a kind of cool behaviour." (Expert \#1)

Tax evasion and cheating are often considered "games" or "tricks" people play, indicating a combination of euphemistic labeling and the diffusion of responsibility, according to Expert \#1: “(It's a) common play, everybody knows that everybody does it." Ordinary Hungarians perceive corruption as pervasive. The fact that they observe grand corruption on a daily basis illustrates the diffusion of responsibility and reinforces Hungarians' self-esteem related to behaving in a "smart" and "cool" manner (Expert \#1).

Identity-based and intergroup behaviors related to victimhood and cleverness are revealed through several moral disengagement mechanisms, such as diffusion of responsibility and attribution of blame, as illustrated by Expert \#1: "Most of (the) people want to cheat the state. And this might be very historical because Hungary was occupied (...) for many years (...) by foreign powers.” They also use denial of harmful effects and advantageous comparisons: "People don't feel like a tax-payer. They feel that we are against the state and the state is something above us or against us. And if you can trick something, so we don't pay tax for the state, it's good" (Expert \#1).

The bifurcated relationship with the state also extends to the EU and is revealed by the so-called "kuruc" mentality: "This nationalistic mentality, which is a kind of bashing the $E U$, bashing the foreign powers, (...) implies a kind of selfvictimization that derives from the Trianon trauma" (Expert \#2).

However, in Hungary, multinational enterprises (MNEs) that emphasize clean business practices might be able to make a difference. Expert \#3 noted that Hungarians working for Western MNEs internalize their value systems: "I wouldn't imagine them engaging in corruption of any kind, simply because it just seems like people have really internalized the values of the company. And they talked about (the $M N E)$ being this (...) really ethical company." In reference 
to German and UK upper management, Expert \#3 noted that the Hungarians wanted to "show them what we can do. And, you know, we want to impress them" to show them that Hungarians are not "backwards people from communism, who think like communists."

Such insight into the Hungarian social identity is remarkable, since Hungarians working for Hungarian companies did not change their behavior. This indicates the significance of the environment in structuring unethical behavior within the logic of triadic co-determination. Expert \#3 explains, "But working for Hungarian company, you might be like, (...) 'what's the point of me trying to be moral and clean, because it's not even going to be appreciated and potentially people might (...) make it more difficult for me."”.

\section{North Macedonia}

"Every country has a mafia but only in Macedonia does the mafia have a country." (Hislope, 2002, p. 33)

To outsiders, the quote above may seem like a sensationalistic over-dramatization. After all, North Macedonia is the birthplace of Alexander the Great, whose empire provided an important building block for Western civilization. In addition, the events of the early 2000s, which unfolded in a perfect storm of ethnic tensions typical of the region and of the growing pains of transition societies, have passed. This fledgling Western Balkan state gained independence in the early 1990s in the aftermath of Yugoslavia's bloody disintegration and became an EU candidate country before Croatia.

Unfortunately, the mirage of an "oasis of peace" has been shattered by organized crime, corruption and political turmoil, turning North Macedonia into an "oasis of corruption and crime" (Hislope, 2002, p. 33). It also illustrates a vicious cycle of the "social psychology of evil" (Zyglidopoulos \& Fleming, 2008, p. 267), part of a dynamic social structuration process (and not just an external environment variable). Supplying Europe, the Balkan drug super-highway, runs across North Macedonia (Hislope, 2002).

The 2017 political pivot and the exile of former Prime Minister Nikola Gruevski, who ended up in Hungary, spurred cautious hope over new signs of democratization and attempts to address corruption. Mr. Gruevski personified the grandiose, grotesque, Alexandrian nationalistic renaissance of Macedonia (Vangelov, 2019). However, despite this political change, North Macedonia remains plagued by organized crime and populist political elites, its society and economy paralyzed by the unprecedented brain drain of over a quarter of its population. Those who remain are at the mercy of negative selection, creating a dangerous backsliding dynamic (Vangelov, 2019).

The 2008 Greek veto of Macedonia's joining NATO due to the name issue (as Macedonia is also a region in the north of Greece) gave rise to Gruevski's identity politics and set in motion a physical, cultural and philosophical transformation of Macedonian society to boost collective self-esteem. The 2014 Skopje development project turned the capital into a grotesque, autocratic, ethno-nationalistic theme park that included brass statues, neo-Hellenic marble architecture and even a galley ship in a land-locked country (Vangelov, 2019).

Despite the country's political pivot and institutional attempts to tackle corruption and organized crime (as part of an "institutional guillotine," according to Expert \#6) and the contested name change to North Macedonia, the country's path to officially begin EU negotiations remains uncertain. This might cause Macedonian society to turn away from Europe and slide back into a familiar pattern of false certainty offered by populist politics.

This stark picture emerged from our experts and supplementary literature. The ubiquitous nature of corruption in North Macedonia sets the stage for the environment component of our framework, as highlighted by Expert \#4: "So today, in modern Macedonia, I would say corruption is everywhere (...). Basically, people do not perceive it as a very negative thing, mainly because the country is very small, (it has) very limited resources." It also shows signs of social and economic justification, a type of moral disengagement mechanism.

Even more telling, corruption in North Macedonia does not acknowledge in-group/out-group social boundaries, according to Expert \#4: "(C)orruption happens among friends and they are not even aware that they're kind of doing (it)." Derived from an ancient Ottoman tradition of gifting officials coffee, it seems to have much deeper historical and cultural roots than in other CEE countries:

"Macedonia used to be part of the Ottoman Empire for 500 years, which was, in a sense of governance and organization of the society (...) very different from the Western societies (...). Unfortunately, those habits stayed until today." (Expert \#5)

This ubiquity is present also in the private sector, where euphemistic labeling is often used to normalize it: "(I)t's pretty pervasive in especially those businesses that engage in trade. If you're doing trade, you just have to 'grease the machine.' You have to bribe the customs officers. (...) it's just 'part of the game." (Expert \#6).

MNEs have also adopted this type of normalized behavior: "foreign companies have actually become very complicit" in perpetuating the cycle of corruption, although "the common sense is that they (MNEs) are somehow more reliable than the domestic actors. So, they're not considered infallible, but comparatively, a bit more decent than domestic actors" (Expert \#6). However, foreign companies 
have gone beyond being complicit, changing the regulatory landscape and institutions:

"Foreign companies introduced the practice of lobbying. I mean, lobbying was always there, but this legal lobbying and this ability to exercise leverage in the formulation of regulatory frameworks (...). So, a lot of laws actually have been amended, and these laws pertain to worsening of labor conditions and sustainability issues." (Expert \#6)

Macedonians' self-enhancement increases when working for a foreign company. This suggests the emancipatory potential of MNEs and their symbolic capital:

" $(T)$ here is this kind of notion of internalized Orientalism (...) when you embrace all the negative stereotypes about the Balkans, about Macedonia and you kind of internalize the notion that you are worth less than the Westerners. And when you position yourself not just in the interactions, but in general in your attitude towards the world, as 'Okay, I'm from this country and I'm less because I'm from here.' So, in some sense, for many people working for a foreign company has an emancipatory potential. You know, this kind of symbolic power, especially German companies, Germany quality, German working culture." (Expert \#6).

Employment with MNEs improves self-esteem and efficacy, allowing MNEs to take advantage of this and pay lower wages, according to Expert \#6: "They would accept even less financial capital (compensation) because there's so much symbolic capital being conveyed in them being affiliated with a foreign company." For those not employed by MNEs, system escape is the only alternative. This has led to massive brain drain that has robbed the country of social change: "You cannot do anything if you're not connected to any of the political parties, and that, some people (...) don't accept. They simply sell everything and go." (Expert \#5).

In addition to grand corruption involving kickbacks and state capture, everyday petty corruption goes beyond typical normalized unethical behavior and indicates strong social agency: "[C]orruption, it's simply in a way voluntary, because people are trying to bribe the officials, the doctors, the professors (...) in order to get some better treatment or in order to get the service at all' (Expert \#4).

The context of North Macedonia's social identityscape differs from that of other CEE countries. The nationalistic populist rhetoric employed by the politicians, especially the former prime minister, was not driven by ordinary people's self-esteem needs, but was a way of reducing collective and individual uncertainty: "(Macedonians) admit that basically social development, and the political, and economic is not as high as in Western Europe; and usually (...) we honestly say that we are far behind in this sense" (Expert \#4).
Such pragmatism moderates the usual mechanisms of optimal distinctiveness seen in other CEE countries, in which one compares oneself not only to Western or Eastern Europeans, but also to various implicit hierarchies within CEE, according to Expert \#5: "Macedonians definitely do belong to Eastern Europe, but this is not (...) in a way offensive at all as it usually is for Hungarians." For Macedonians, what seems to matter more is their identification with neighboring countries, regardless of EU membership. According to Expert \#5, Macedonians "identify with the other people on the boat (...) Bulgarians, Greeks, Serbians," showing strong regional identity.

In terms of moral disengagement mechanisms, the majority of everyday citizens seem influenced by a need to survive, as well as complex historical and cultural embeddedness that feeds economic and social justification. For example, Expert \#5 summarized the sentiment: “Okay, if I need to become a member of the political parties to get them (paying jobs), like, then I will be a member of the political party" and "they justify this with small salaries, with the families." This limited locus of moral disengagement is much narrower in the case of North Macedonia compared to the other two countries, according to Expert \#5: "[M]ost of the people work in the public administration. They have small salaries; but you know, when you ask Macedonians, they spend more than they are earning."

The locus of moral disengagement shifts among businesspeople, who often resort to euphemistic labeling (e.g., tricking the state, playing the system) and displacement of responsibility towards the government, the Albanian ethnic group, political parties and the corrupt elites. In a few cases, diffusion of responsibility may also be present, particularly for petty corruption. However, even here, it is difficult to disentangle the behavioral locus of disengagement (socioeconomic justification) from the agentic one (diffusion of responsibility).

\section{Slovenia}

"Slovenian model of 'neo-corporativist' social democracy has been (...) a conscious attempt to preserve not only equality and social justice, but also as much as possible from the former communist system." (Bugaric \& Kuhelj, 2015, p. 274)

Slovenia is in many ways a victim of its early socialist successes and transition. According to Expert \#9, "Slovenia was considered a wonder child of post-socialist transition," rendering it reluctant to pursue systematic structural reforms. Such complacency has enabled the flourishing of a self-consuming neo-corporatist institutional ecosystem of elites (Bugaric \& Kuhelj, 2015). According to Expert \#7, "The most typical type of corruption in Slovenia is state 
capture by domestic actors," which is linked to a slow and unfinished privatization process. Expert \#8 clarified further: “(W)e are striving with pretty big aspects of corruption in many ways in managing state owned enterprises or state of assets.”

Based on our interviews, corruption does not arise from necessity or culture. Nor does it seem to deviate much from corruption in much of Western Europe, to which Slovenia likes to compare itself in a quest to distinguish its recent Yugoslav history from its European identity. Expert \#8 provided a colorful example that highlights the underlying self-esteem nature of strong pro-European identification: "I would say that we are pretty good Europeans (...), we are pro-European, that we like to be in European Union, and to be part of the bigger story."

Slovenian self-esteem mixes with a particular type of optimal distinctiveness, seeking to transcend the concept of East Europeanness symbolized by the Visegrad group of countries and its link to the Western Balkans. A quote by Expert \#8 points to a glaring example of advantageous comparison: " $(W)$ e are also highly regarded in comparison to others, especially ex-Yugoslavian or Eastern European nations, like Slovakia, Czech Republic, Poland, especially Hungary." Such optimal distinctiveness might be a way of compensating for a lack of a richer history, as Slovenia was never independent prior to 1991. This is also reflected in its national character, with obvious implications for corruption and the reconciliation of unethical behavior, according to Expert \#8: "We are a mixture of something in between of German punctuality and strictness, mixed with Yugoslavian laziness and trying to go over the limits passing the rules."

When it comes to corruption, Slovenians again draw on optimal distinctiveness and compare themselves to ex-Yugoslavs while believing they "meet the standards" of Western Europe. This is evident in comments in which Expert \#8 discussed petty and public types of corruption: "Petty corruption is not a huge problem as I would say, as we would say it is in ex-Yugoslavian countries." The expert contrasted this with:

"Every Western, more or less developed country, which Slovenia, I believe it is, we have also seen different aspects of corruption in that respect, meaning that (...) corruption and probably procurement is pretty big again connected with close relationships and lack of proper competition." (Expert \#8)

Although greed seems to be the main driver of white-collar crime in the case of state capture, our experts explained most other corruption through the so-called fraud triangle. According to Expert \#8, in Slovenia, this triangle consists of the following: (1) a demonstrated need via clientelist motives, nepotism and political cronyism (especially in public procurement and kickbacks) that is (2) enabled by the perfect storm of opportunities arising from transition (e.g., management and privatization of state assets, managerial buyouts, media independence) and completed by (3) rationalization mechanisms related to opportunism and a sense of entitlement. One aspect of this emerges through the moral disengagement mechanism of socioeconomic justification, which is further linked to strong work centrality within collective self-esteem (Abrams \& Hogg, 1990):

"I worked my ass off (...) and I deserve this. Nobody else deserves it. And I did it all by myself. It can be an opportunity, in terms of: OK, I am taking this because I'm here and I haven't done anything wrong in the past." (Expert \#8)

It is also linked to disregard for or denial of consequences:

"So, the person says, 'Yeah, I stole, I don't know, hundred thousand $\mathrm{K}$ from the state budget,' there is no direct consequence, which you could pinpoint to that person. Then five people there in the hospital didn't receive proper treatment because of that; hence they died because of it, for example." (Expert \#8)

A slow and ill-experienced institutional ecosystem, especially one related to lobbying regulation and judiciary practice, which, according to Expert \#8 "is not properly established," perpetuates the fraud triangle. It is further accompanied by a general lack of accountability at the individual and institutional levels. One expert described a case in which a leading political party received an illegal 200,000-euro loan from the Balkans as follows:

"(T)he court which directs you to supervisory body for party financing issued them the highest penalty, which is 20,000 euros $(\ldots)$ then it needed to be approved by the (...) proper court in Slovenia, which basically (...) first it reduced this penalty to 5,000 euros and then the party appealed, and they basically got away without the penalty." (Expert \#8)

Such a lack of political accountability and its institutional sanctioning facilitates a third type of moral disengagement mechanism related to agency. Specifically, this is the displacement of responsibility, which trickles down from the top to the individual, as described above. Diffusion of responsibility, as the fourth agentic moral disengagement mechanism, is less pronounced, more benign and mostly limited to the grey economy, according to Expert \#7: "The system is such and everybody does it. But I don't think we should look at it this way." Expert \#8 described Slovenians' sociocultural environment as follows:

“(...) the biggest problems we are facing are (...)

I would sum up us coming out from the country, which is really small, which basically means that 
everyone knows everyone. So, nepotism and clientelism is something which I would highlight as one of the biggest issues."

According to Expert \#7, Slovenians' high savings rate can be explained by risk aversion: "Slovenians are not big riskers. They are more risk averse (...) this translates then, that they are afraid of not following the rules." This risk aversion is also illustrated by their use of euphemistic labeling when referring to tax avoidance as optimization, according to Expert \#8. Although the close, small environment encourages the development of tight identitybased norms, as well as facilitating nepotism and clientelism, the egalitarian and tall-poppy-syndrome culture of never sticking out also has a positive effect on curbing corruption via jealous neighbors:

"If Slovenians see that the neighbor has better cow (...) they are jealous and they report. This also reflects when it comes to corruption (...) allegations come in majority from the citizens. The citizens are the ones that report the most." (Expert \#7).

According to Expert \#9, the urban-rural divide provides not only different business opportunities, but also a basis for social comparison, giving rise to various forms of justification: "(I)f we were in Ljubljana, we would be doing better because there were all the networks there and everybody is somehow connected." Social justification is even stronger and assumes moral undertones: "There's definitely this perception of Ljubljana having very dubious moral practices (...) I'm a pure person from a rural part of Slovenia and would never engage (in such) morally dubious practices" (Expert \#9).

However, business owners often justify engaging in corrupt practices based on perceived need and strong core-periphery categorizations, according to Expert \#9: "Corrupt Ljubljana elite, they have everything (...) while we on the periphery, we don't have nothing, and that's why we need to do stuff like this. This is the only way we can survive." Egalitarianism and the tall poppy syndrome also facilitate opportunities within the fraud triangle, as illustrated by Expert \#8: "Slovenian managers and politicians are not well paid compared to other European countries (...) which might trigger this behavior, unethical or illegal behavior." This points to a fifth social moral disengagement mechanism related to advantageous comparison and social identity. Expert \#7 observed the following in terms of understanding moderate levels of corruption in Slovenia: "The culture here plays a major role for Slovenians (...) They like their country. Slovenians love Slovenia. Not some of the elites, but general public, they love it."

\section{Discussion}

We set out to explore three post-socialist CEE countries marred by communist legacies (Padelford \& White, 2010), where corruption is seen as a social institution (Enderle, 1997) normalized through a complex set of social psychology processes (Zyglidopoulos \& Flemming, 2008). We have adopted a non-positivist approach and presented an integrated social psychology framework which goes beyond cultural determinism and the "game rules" structure-dominant logic of new institutional economics (Aguilera \& Grøgaard, 2019) to explore more "the purposive action of individuals and organizations aimed at creating, maintaining and disrupting institutions" (Lawrence \& Suddaby, 2006, p. 215). Given the sociocognitive nature of our framework, we focused more on the cognitive aspects of institutions and less on the normative and regulative pillars within institutional theory (Aguilera \& Grøgaard, 2019). We explored the interaction between moral agency and social interactionism through the logic of Bandura's $(1986,2016)$ triadic co-determination, which links cognition, the social and physical environment and behavior; topics seldom explored jointly in existing research on corruption (Bahoo et al., 2020) and in multi-country studies (Enderle, 1997).

We were interested in exploring moral disengagement mechanisms Hungarians, Macedonians and Slovenians use to realign their social cognition with behavioral transgressions they commit as purposeful agents or witness as innocent bystanders (Zyglidopoulos \& Flemming, 2008) to co-create their social environment, by drawing on social structuration, embeddedness and identity-based intergroup behavior. Finally, we also explored the outcomes of these processes with respect to corruption and types of social identity (underpinned by specific motivational mechanisms).

The systematizing expert interview methodology, which was structured around an established corruption narrative typical of CEE, yielded reflective knowledge by our experts regarding how various actors in the three studied CEE countries, such as private citizens interacting with business and government, as well as business owners, entrepreneurs and employees, live with and reconcile corrupt practices daily. Experts informed us about the sociocognitive processes underpinning corruption and highlighted distinctive types of moral disengagement individuals and groups use to justify or reconcile living with corruption. The opinions provided by our corruption experts indicate the relevance of exploring the sociocognitive aspects of normalized corruption, as a type of institution, and the need to look beyond organizational boundaries when exploring corruption in the business 
environment in order to understand the structure of the environment and various exogenous factors to which actors respond. Experts indicated that collective corruption can be normalized well beyond organizational boundaries (Ashforth \& Anand, 2003; Brief et al., 2001) by complex social agentic forces that combine moral agency, social structuration and identity politics.

The interviews revealed that after the fall of the Iron Curtain, driven by long awaited political and economic freedom and desire to emulate Western Europe, complex and intersecting social identities emerged, steeped in history and fraught with identity politics (Rašković et al., 2020). Some of these identities and accompanying practices are evocative of and motivated by national historical events, especially in the cases of Hungary and North Macedonia. Others are more future oriented, with individuals seeing themselves more as Europeans. This suggests the divergence of CEE as a collective identity space (Rašković et al., 2020).

\section{Synthesis of Key Findings: Specific Sociocognitive Patterns of Normalized Corruption}

Viewing expert interviews through our framework (Fig. 1), a number of important patterns surface from Table 1 pointing to different archetypes of normalized corruption in CEE. The selected quotes from each country appear to converge on a number of themes, illustrating interrelated patterns of social structuration mechanisms (i.e., purposeful actors upholding, strengthening and/or challenging a socially constructed reality of corruption), influence of various types of embeddedness, distinct identity-based group dynamics and a plethora of salient moral disengagement mechanisms. In all three countries, we found widespread evidence of grand corruption and/or white-collar crime that appears to be normalized through institutionalization, rationalization and socialization (Ashforth \& Anand, 2003). Individuals use a combination of moral disengagement mechanisms (Bandura, 1986) to reconcile, or live with unethical and sometimes illegal behavior, including in organizational settings (Moore, 2008).

We observe different patterns of triadic co-determination of cognition, behavior and the environment which provide sociocognitive insights into the current levels of normalized corruption in the three CEE countries. They can also help us think about possible trajectories of change and (d) evolution in the future. Our synthesis from Table 1 points to three archetypes of normalized corruption characterized by specific patterns of moral agency and social interactionism.

In Hungary, a strong tendency towards upholding/maintaining corruption among both individuals and organizations manifests itself in a robust social psychology of survival and an endemic environment of higher-level institutionalized corruption dominated by state capture, extractive institutions and populist politics in which individuals cognitively disconnect from their own social agency. This social structuration tendency is underpinned by pronounced historical, cognitive and political types of embeddedness, which in terms of moral disengagement mechanisms feed into a strong sense of historical victimhood, displacement of responsibility via-a-vis the elites, strong economic and social justifications of survival (where only the clever survive), and a general denial of corruption's consequences among citizens. History mars the Hungarian identity, inhibiting self-efficacy and perpetuating a collective self-esteem of victimhood which seems to have transferred to Hungary's contested relationship with the EU.

In North Macedonia, the tendency to uphold/maintain corruption is stronger among organizations than individuals. Strong historical embeddedness manifests itself in a unique mixture of reviving the glories of Alexander the Great and 500 years of Ottoman influence which support strong political embeddedness (anchored in nationalism and populism), as well as pronounced structural (i.e., corruption through interpersonal relationships) and cultural embeddedness drawn upon by individuals. In terms of moral disengagement mechanisms, strong moral and social justification are typical within the behavioral loci, while the displacement of responsibility within the agentic loci emphasizes the extractive nature of a deliberately broken system benefiting Macedonian and Albanian political elites, as well as foreign MNEs. Denial of consequences is often rationalized in terms of legalized loopholes, while attribution of blame, as part of the victim loci, is connected to a notion of internalized Orientalism and a strong regional identity.

In Slovenia, there is a somewhat stronger pattern of challenging/seeking change which precedes strengthening normalized corruption among individuals and upholding/ maintaining normalized corruption among organizations. While the state of corruption seems to be gradually worsening due to Slovenia's failing neo-corporativist social democratic system, particularly after the global financial crisis, the absence of historical embeddedness and pronounced rule-based cognitive and cultural embeddedness support challenging a regressive trend, perhaps more among individuals than organizations. Political embeddedness is less pronounced and limited to state capture by domestic politics managing state-owned assets from unfinished privatization. When it comes to moral disengagement, mechanisms related to behavioral loci combine economic and social justification with collective self-esteem emphasizing work centrality (i.e., being deserving of something due to hard work), while the agentic loci manifest in typical patterns of displaced responsibility and strong peer (neighbor) comparisons. In terms of identity, Slovenians need to be recognized as good Europeans ahead of Visegrad countries and the rest of CEE, often wanting to set themselves distinctly apart from other ex-Yugoslav nations. 


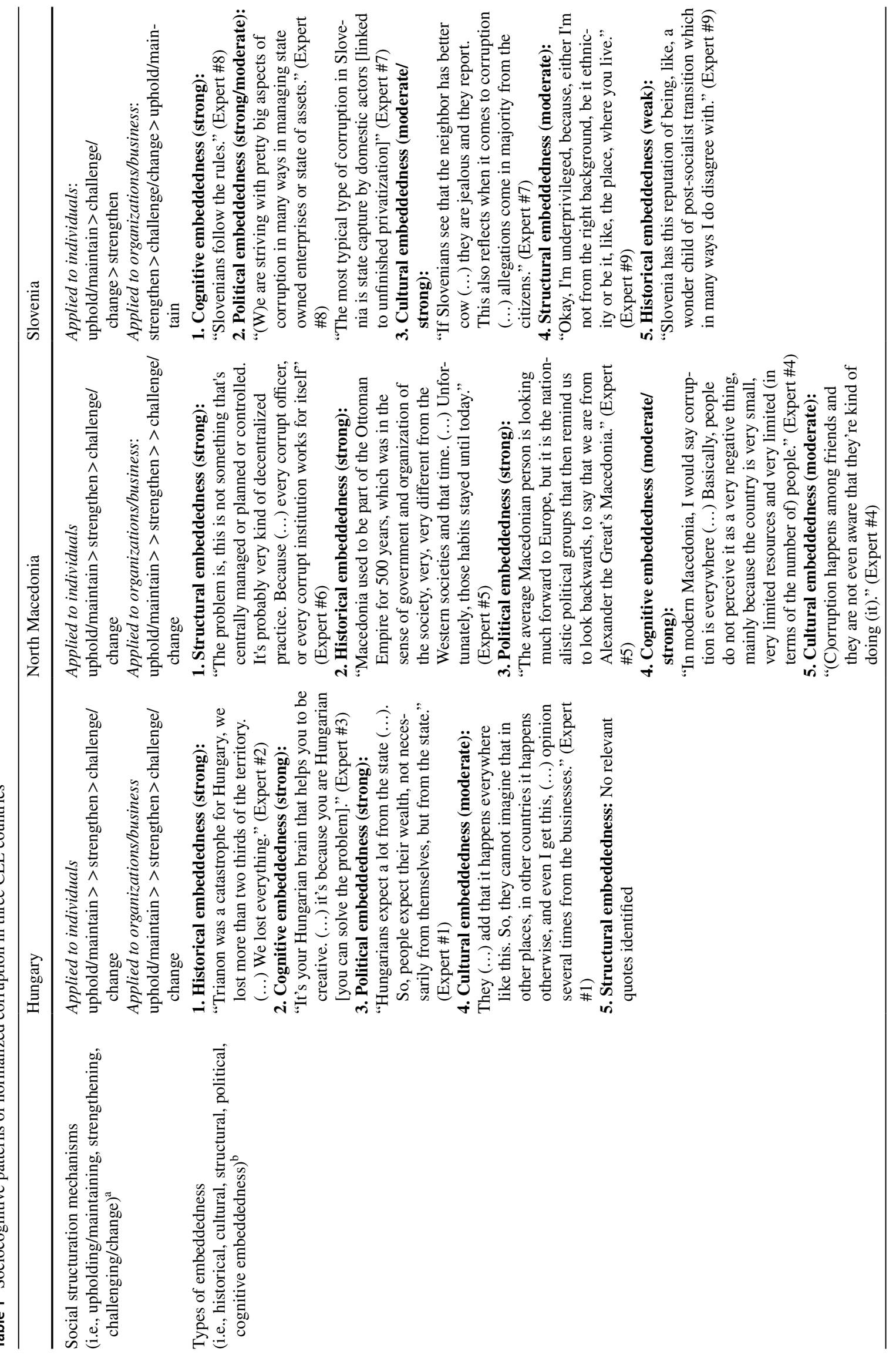




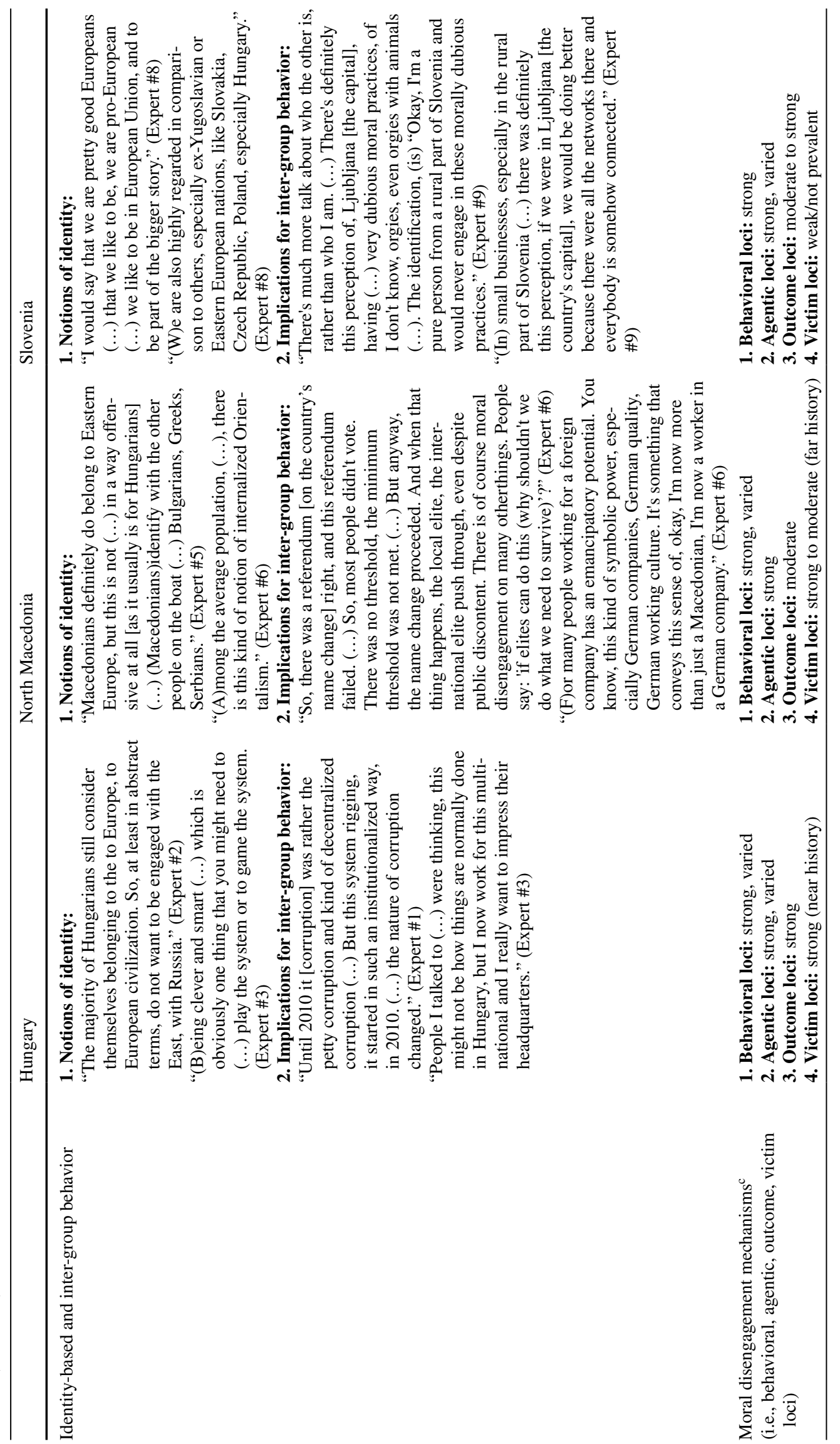




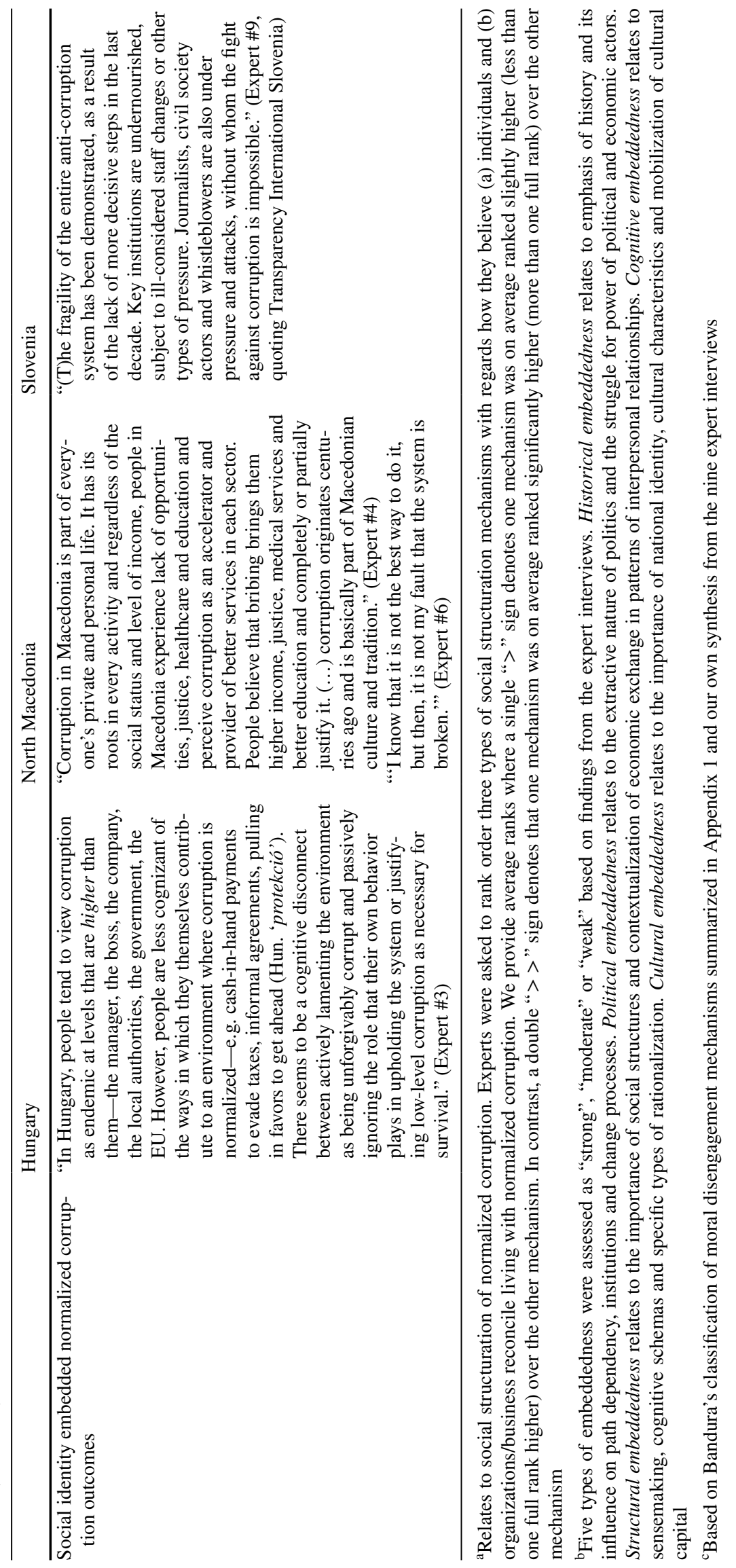




\section{Theoretical and Policy Implications}

Our research carries three types of theoretical and policy implications. First, we must revisit the dichotomous distinction between "public" and "private." Our findings illustrate that existing theory, with its discrete public-private dichotomy, falls short of grasping the complex, nuanced and multi-level nature of corruption, which, in the CEE case, is deeply embedded in history, political systems, social identity (Rašković et al., 2020), and cognition. The influence of the institutional economics strand within institutional theory and the discussion of institutional voids linked to transition processes have meant that corruption research often suffered more the application of "thin" institutional theory (Aguilera \& Grøgaard, 2019) which has treated corruption and its factors as exogenous variables, particularly in multi-country comparisons (Padelford $\&$ White, 2010). In contrast, our research shows that the underlying social psychology behind corruption, as a type of social institution (Enderle, 1997), calls for understanding the cognitive pillar of institutions (Aguilera \& Grøgaard, 2019) and a less structuralist approach in favor of purposive actions and processes of individuals and organizations (Lawrence \& Suddaby, 2006). The value of such an approach is that it can better explore complex, multilayered and multi-level sociocognitive processes driving normalized corruption over time, link them to changes in the country and global environments, and help explain processes of change and transformation. Our paper provides a step in this direction.

Our interviews unveil layered dynamics that require other theories to explain corruption. For example, Gidden's structuration theory might be helpful in understanding corruption as an outcome of dynamic processes of social structuration based on purposeful agency of actors which uphold, strengthen and/or challenge social structures and transcend the constraining/enabling role of institutions as simple "game rules" (see Rašković \& Takacs Haynes, 2020). Such processes are underpinned by complex sociocognitive mechanisms (Aguilera \& Grøgaard, 2019), such as moral disengagement and SIT (Hogg \& Terry, 2000).

Adopting a social psychology perspective can be particularly useful in facilitating a more contextualized theoretical analysis needed in challenging the onto-epistemology of corruption (Castro et al., 2020). It should, for example, disentangle which aspects of corruption in CEE are socioculturally normalized and which are systemic in terms of historical, political and formal institutional structures (Vergara, 2019, p. 3) or which aspects of corruption are underpinned by cognition, behavior and the general environment
(Castro et al., 2020). This stream of research could help clarify which aspects are part of the demand side and which of the supply side of corruption.

Second, although the mainstream business ethics literature has shifted from notions of moral decoupling to exploring the various mechanisms of moral disengagement, this has remained limited to individual and organizational contexts (Moore, 2008). Our study shows that, in the context of corruption, the moral disengagement-social identity nexus must also be explored at the societal level (Newman et al., 2019), where moral and social agency intersect.

Third, as greater attention is being paid to social identity in the context of organizations (Rašković \& Takacs Haynes, 2020), and as SIT continues to evolve towards explaining societal and organizational phenomena (Choi \& Hogg, 2020), scholars and policymakers have a duty of care. In an atmosphere of polarizing identity politics within CEE (Rašković et al., 2020), management scholars must revisit SIT, begin exploring the variety of its motivational mechanisms, and become more familiar with its recent applications (Rašković \& Takacs Haynes, 2020).

By exploring the business side of corruption in CEE and the role of organizations, our research has highlighted that in countries with high levels of FDI and the strong presence of foreign MNEs (e.g., Hungary and North Macedonia) MNEs might be places where social identities (Rašković \& Takacs Haynes, 2020) and morals clash strongly (Moore, 2008). Several of our experts pointed this out quite explicitly, showing how MNEs might be important actors in either perpetuating corruption along a continuum of destructiveness or as agents of change and force for good in corruption-ravaged CEE countries. Quotes about North Macedonia and Hungary point out how MNEs are perceived to elevate host-country employees by providing symbolic capital.

Policymakers at the national and supra-national levels must become more vigilant and proactive in monitoring and managing the polarizing force of identity politics, and managers must become more mindful of them as part of their non-market strategic toolkit. Our work illustrates that corruption is deeply rooted in individuals' social identification and is based on their beliefs, values, sense-making mechanisms and cognitive schemas, all of which drive them to act in certain ways, thereby creating, maintaining and perpetuating ethical and unethical practices in their environment. These individual- and grouplevel actions and processes uphold, strengthen and/or support challenging corruption, as a social institution (Enderle, 1997). This takes places through the cognitive pillar of institutions at the macro level (Aguilera \& Grøgaard, 2019) and actions by purposive actors at the micro level (Lawrence \& Suddaby, 2006). 


\section{Conclusion}

Our study has some limitations, one of which might be the expert interview methodology. Reliance on experts is an accepted practice in the management literature (Haynes et al., 2017) due to the method's numerous benefits, which include deep knowledge of the subject matter and the ability to provide information in an analytical and scientific manner. Furthermore, it can help overcome several obstacles in conducting meaningful research on corruption (Castro et al., 2020). Our experts' deep understanding of their fields is evidenced by their formal education and standing (seven out of nine hold $\mathrm{PhDs}$ in their fields). However, due to the small size of the studied countries, as well as the limited number of subject matter experts for creating matched panels, we were able to secure only three interviews in each country. It is possible that our experts were unable to provide a full account of all the details surrounding social identities and moral disengagement. Interviews with a larger number of experts could mitigate these shortcomings, as could a different methodology, such as country case study, discourse analysis or theory-generating expert interviews. We recommend future research explore these options.

In this study, we applied several theoretical lenses to build an integrated social psychology framework to explore normalized corruption in three CEE countries and address various sociocognitive patterns of such corruption in a non-positivist manner. Although the streams of literature based on SIT, social cognitive theory and moral disengagement are rich, they have not, to the best of our knowledge included examinations of corruption in the CEE context. While CEE has provided fertile research ground for the advancement of institutional theory, it has adopted a macrolevel structuralist perspective (Rašković et al., 2020) and has been less interested in the social structuration of corruption by purposive actions of individuals and organizations at the micro level (Aguilera \& Grøgaard, 2019).

At the core of our framework are social identities that, through self-enhancement, optimal distinctiveness and uncertainty reduction motives, influence individual cognition and values, behaviors, and the institutional and organizational environments where corruption occurs. Through processes of social structuration and identity-based behaviors, groups and individuals in CEE live with, co-create and in some cases also challenge normalized corruption, invoking moral disengagement to resolve the tension between social identity and conduct.

\section{Appendix}

See Table 2.

Table 2 Bandura's moral disengagement mechanisms with definitions

\begin{tabular}{|c|c|c|}
\hline Moral disengagement mechanism & Definition & Locus \\
\hline Moral, economic or social justification & $\begin{array}{l}\text { Converts harmful conduct into beneficial conduct by sanctifying "harmful means to achieve } \\
\text { worthy ends." }\end{array}$ & Behavior \\
\hline Euphemistic labelling & $\begin{array}{l}\text { Changes harmful into beneficial through "sanitizing and convoluted language", and "special- } \\
\text { ized jargon." }\end{array}$ & Behavior \\
\hline Advantageous comparison & $\begin{array}{l}\text { Is self-exoneration by cloaking a behavior so that the lesser of two evils is acceptable and } \\
\text { even morally right }\end{array}$ & Behavior \\
\hline Displacement of responsibility & Obscures or minimizes one's agentic role by deferring responsibility to an authority & Agentic \\
\hline Diffusion of responsibility & $\begin{array}{l}\text { Diminishes one's personal responsibility by invoking group decision-making, division of } \\
\text { labor and collective action }\end{array}$ & Agentic \\
\hline Denial of consequences & $\begin{array}{l}\text { Inattention to harmful effects by minimizing harm, discrediting evidence of harm and keep- } \\
\text { ing harmful effects out of sight }\end{array}$ & Outcome \\
\hline Attribution of blame & Is self-exoneration by blaming the adversary, or circumstances & Victim \\
\hline Dehumanization & Is denial of humanness or human attributes of another & Victim \\
\hline
\end{tabular}

Descriptions and definitions from Bandura (2016), pp. 48-66 
Supplementary Information The online version contains supplementary material available at https://doi.org/10.1007/s10551-021-04927-9.

\section{Declarations}

Conflict of interest The authors declare that they have no conflict of interest.

Ethical Approval All procedures performed in studies involving human participants were in accordance with the ethical standards of the corresponding author's institutional and/or national research committee of the University of Delaware, Newark, DE, USA (reference number 1454509-1) and with the 1964 Helsinki declaration and its later amendments or comparable ethical standards. Exemption from a full review was granted by the University of Delaware (Newark, DE, USA) Institutional Review Board for the expert panel interviews, since the panel members were interviewed as subject matter experts and asked to provide only their professional opinion.

\section{References}

Abrams, D., \& Hogg, M. A. (1990). Social identity theory: Constructive and critical advances. Prentice Hall.

Abrams, D., \& Hogg, M. A. (2004). Metatheory: Lessons from social identity research. Personality and Social Psychology Review, $8(2), 98-106$.

Aguilera, R., \& Grøgaard, B. (2019). The dubious role of institutions in international business: A road forward. Journal of International Business Studies, 50(1), 20-35.

Ashforth, B. E., \& Anand, V. (2003). The normalization of corruption in organizations. Research in Organizational Behavior, 25, $1-52$.

Bahoo, S., Alon, I., \& Paltrinieri, A. (2020). Corruption in international business: A review and research agenda. International Business Review, 29(4), 101660.

Bandura, A. (1982). Self-efficacy mechanism in human agency. American Psychologist, 37(2), 122-147.

Bandura, A. (1986). Social foundations of thought and action. Prentice-Hall.

Bandura, A. (1999). Moral disengagement in the perpetration of inhumanities. Personality and Social Psychology Review, 3(3), 193-209.

Bandura, A. (2016). Moral disengagement. How people do harm and live with themselves. Macmillan Learning.

Bogner, A., Littig, B., \& Menz, W. (2018). Generating qualitative data with experts and elites. In U. Flick (Ed.), The SAGE handbook of qualitative data collection (pp. 652-667). Sage Publications.

Bogner, A., \& Menz, W. (2009). The theory-generating expert interview: Epistemological interest, forms of knowledge, interaction. In A. Bogner, B. Littig, \& W. Menz (Eds.), Interviewing experts (pp. 43-80). Palgrave Macmillan.

Bohatá, M. (1997). Business ethics in Central and Eastern Europe with special focus on the Czech Republic. Journal of Business Ethics, 16(4), 1571-1577.

Brand, V. (2009). Empirical business ethics research and paradigm analysis. Journal of Business Ethics, 86(4), 429-449.

Brief, A. P., Buttram, R. T., \& Dukerich, J. M. (2001). Collective corruption in the corporate world: Toward a process model. In M. E. Turner (Ed.), Applied social research. Groups at work: Theory and research (pp. 471-499). Lawrence Erlbaum Associates Publishers.

Brouthers, L. E., Lascu, D.-N., \& Werner, S. (2008). Competitive irrationality in transitional economies: Are communist managers less irrational? Journal of Business Ethics, 83(3), 397-408.

Brown, W. S., McCabe, D., \& Primeaux, P. (2003). Business ethics in transitional economies: Introduction. Journal of Business Ethics, 47(4), 295-297.

Bugaric, B., \& Kuhelj, A. (2015). Slovenia in crisis: A tale of unfinished democratization in East-Central Europe. Communist and Post-Communist Studies, 48(4), 273-279.

Castro, A., Phillips, N., \& Ansari, S. (2020). Corporate corruption: A review and research agenda. Academy of Management Annals. https://doi.org/10.5465/annals.2018.0156

Choi, E. U., \& Hogg, M. A. (2020). Self-uncertainty and group identification: A meta-analysis. Group Processes \& Intergroup Relations, 23(4), 483-501.

Cuervo-Cazurra, A. (2008). Better the devil you don't know: Types of corruption and FDI in transition economies. Journal of International Management, 14(1), 12-27.

Dixon, S. E., Meyer, K. E., \& Day, M. (2010). Stages of organizational transformation in transition economies: A dynamic capabilities approach. Journal of Management Studies, 47(3), 416-436.

Döringer, S. (2020). 'The problem-centred expert interview'. Combining qualitative interviewing approaches for investigating implicit expert knowledge. International Journal of Social Research Methodology, 24(3), 265-278.

Enderle, G. (1997). A worldwide survey of business ethics in the 1990s. Journal of Business Ethics, 16(14), 1475-1483.

Fazekas, M., \& Toth, I. J. (2016). From corruption to state capture: A new analytical framework with empirical explanations from Hungary. Political Research Quarterly, 69(2), 320-334.

Filatotchev, I., Starkey, K., \& Wright, M. (1994). The Ethical challenge of management buy-outs as a form of privatisation in Central and Eastern Europe. Journal of Business Ethics, 13(7), 523-532.

Froschauer, U., \& Lueger, M. (2009). Expert interviews in interpretive organizational research. In A. Bogner, B. Littig, \& W. Menz (Eds.), Interviewing experts (pp. 217-234). Palgrave Macmillan.

Fülöp, G., Hisrich, D. R., \& Szegedi, K. (2000). Business ethics and social responsibility in transition economies. Journal of Management Development, 19(1), 5-31.

Haynes, K. T., Campbell, J. T., \& Hitt, M. A. (2017). When more is not enough: Executive greed and its influence on shareholder wealth. Journal of Management, 43(2), 555-584.

Highhouse, S., Broadfoot, A., Yugo, J. E., \& Devendorf, S. A. (2009). Examining corporate reputation judgements with generalizability theory. Journal of Applied Psychology, 94(3), 782-789.

Hislope, R. (2002). Organized crime in a disorganized state: How corruption contributed to Macedonia's mini-war. Problems of PostCommunism, 49(3), 33-41.

Hogg, M. A. (2006). Social identity theory. In P. J. Burke (Ed.), Contemporary social psychological theories (pp. 111-136). Stanford Social Sciences/Stanford University Press.

Hogg, M. A., \& Terry, D. J. (2000). Social identity and self-categorization processes in organizational contexts. Academy of Management Review, 25(1), 121-140.

Hogg, M. A., Terry, D. J., \& White, K. M. (1995). A tale of two theories: A critical comparison of identity theory with social identity theory. Social Psychology Quarterly, 58(4), 255-269.

Huberts, L. W. J. C. (1998). What can be done against public corruption and fraud: Expert views on strategies to protect public integrity. Crime, Law and Social Change, 29(2-3), 209-224.

Jiménez, A., Russo, M., Kraak, J. M., \& Jiang, G. F. (2017). Corruption and private participation projects in Central and Eastern Europe. Management International Review, 57(5), 775-792.

Khera, I. P. (2001). Business ethics east vs. west: Myths and realities. Journal of Business Ethics, 30(1), 29-39.

Lawrence, T. B., \& Suddaby, R. (2006). Institutions and institutional work. In S. R. Clegg, C. Hardy, T. B. Lawrence, \& W. R. Nord 
(Eds.), Handbook of organization studies (2nd ed., pp. 215-254). Sage.

Lendvai, P. (2003). Hungarians: A thousand years of victory in defeat. Princeton University Press.

Lendvai, P. (2019). The transformer: Orban's evolution and Hungary's demise. Foreign Affairs, 98(5), 44-54.

Moore, C. (2008). Moral disengagement in process of organizational corruption. Journal of Business Ethics, 80(1), 129-139.

Newman, A., Le, H., North-Samardzic, A., \& Cohen, M. (2019). Moral disengagement at work: A review and research agenda. Journal of Business Ethics, 167(1), 535-570.

O'Reilly, M., \& Parker, N. (2013). "Unsatisfactory saturation”: A critical exploration of the notion of saturated sample sizes in qualitative research. Qualitative Research, 13(2), 190-197.

Padelford, W., \& White, D. W. (2010). The Influence of historical socialism and communism on the shaping of a society's economic ethos: An exploratory study of Central and Eastern Europe. Journal of Business Ethics, 97(1), 109-117.

Power, S. A., Velez, G., Qadafi, A., \& Tennant, J. (2018). The SAGE model of social psychological research. Perspectives on Psychological Science, 13(3), 359-372.

Rašković, M., Dikova, D., \& McDougall-Covin, T. (2020). International business with Central and Eastern Europe: From tyranny of history to revisited laboratories of learning. Journal of Business Research, 108, 417-420.

Rašković, M., \& Takacs Haynes, K. (2020). (Re)discovering social identity theory: An agenda for multinational enterprise internalization theory. Multinational Business Review. https://doi.org/10. 1108/MBR-02-2020-0031

Rodriguez, P., Uhlenbruck, K., \& Eden, L. (2005). Government corruption and the entry strategies of multinationals. Academy of Management Review, 30(2), 383-396.

Soulsby, A., \& Clark, E. (2007). Organizational theory and the postsocialist transformation: Contributions to organozational knowledge. Human Relations, 60(10), 1419-1442.

Spicer, A. (2009). The normalization of corrupt business practices: Implications for integrative social contracts theory (ISCT). Journal of Business Ethics, 88(Supplement 4), 833-840.
Staub, E. (1999). The roots of evil: Social conditions, culture, personality, and basic human needs. Personality and Social Psychology Review, 3(3), 179-192.

Steger, T., Lang, R., \& Rybnikova, I. (2017). Management in CEE countries between 1996 and 2016: Emerging and Enduring Issues. Journal of East European Management Studies, 22, 1-48.

Tajfel, H., \& Turner, J. C. (1979). An integrative theory of inter-group conflict. In W. G. Austin \& S. Worchel (Eds.), The social psychology of intergroup relations (pp. 33-47). Brooks-Cole.

Tihanyi, L. (2020). From "that's interesting" to "that's important." Academy of Management Journal, 63(2), 329-331.

Transparency International. (2019). Eastern Europe \& Central Asia: Weak Checks and Balances Threaten Anti-Corruption Efforts. Retrieved from https://www.transparency.org/news/feature/weak checks_and_balances_threaten_anti_corruption_efforts_across_ eastern_eu

Uhlenbruck, K., Meyer, K. E., \& Hitt, M. A. (2003). Organizational transformation in transition economies: Resource-based and organizational learning perspectives. Journal of Management Studies, 40(2), 257-282.

Vangelov, O. (2019). The primordialisation of ethnic nationalism in Macedonia. Europe-Asia Studies, 71(2), 203-224.

Vergara, C. (2019). Corruption as systemic political decay. Philosophy and Social Criticism. https://doi.org/10.1177/0191453719868265

Weick, K. E. (2003). Enacting an environment: the infrastructure of organizing. In R. Westwood \& S. Clegg (Eds.), Debating Organization: Point-Counterpoint in Organization Studies (pp. 184-194). Oxford: Blackwell Publishing.

Westerman, J. W., Beekun, R. I., Stedham, Y., \& Yamamura, J. (2007). Peers versus national culture: An analysis of antecedents to ethical decision-making. Journal of Business Ethics, 75(3), 239-252.

Zyglidopoulos, S. C., \& Fleming, P. J. (2008). Ethical distance in corrupt firms: How do innocent bystanders become guilty perpetrators? Journal of Business Ethics, 78(1), 265-274.

Publisher's Note Springer Nature remains neutral with regard to jurisdictional claims in published maps and institutional affiliations. 